\title{
EL MANIFIESTO DE LA BRIGADA AL-JANSA SOBRE EL PAPEL DE LA MUJER EN EL NUEVO CALIFATO ISLÁMICO: UN DESAFÍO AL FEMINISMO Y LA IGUALDAD DE GÉNERO EN EL MUNDO ÁRABE
}

\author{
Olga TORRES \\ Universidad de Sevilla
}

Recibido: 04/07/2015

Aceptado: 26/08/2015

\section{Resumen}

En enero de 2015, la Brigada al-Jansa -sección femenina del autodenominado Estado Islámico- dio un paso más en sus hasta entonces funciones de propaganda, reclutamiento y policía moral al difundir un manifiesto en el que se detalla el papel destinado a la mujer en el nuevo califato. El análisis de este documento pone de relieve el renovado desafío a que está sometida la igualdad de género en el mundo árabe por parte del rigorismo islámico, a la vez que cierta similitud con otras manifestaciones del mismo tenor fundamentalista y antifeminista que se vienen observando en entornos no araboislámicos.

Palabras clave: Brigada al-Jansa, igualdad de género, involución, fundamentalismo rigorista.

\begin{abstract}
In January 2015, al-Khansaa Brigade -female section of the self-styled Islamic Statewent a step further in his hitherto functions of propaganda, recruitment and moral police to disseminate a manifesto detailing the role of women in the new caliphate. The analysis of this document reveals the renewed challenge gender equality is facing in the Arab world before Islamic rigorism, as well as some similarities with other manifestations of the same fundamentalist and antifeminist tenor in non Arab Islamic environments.
\end{abstract}

Keywords: Al-Khansaa Brigade, gender equality, involution, rigorist fundamentalism.

Feminismo/s 26, diciembre 2015, pp. 101-121

DOI: $10.14198 / \mathrm{fem} .2015 .26 .06$ 



\section{Introducción}

El llamado Estado Islámico tiene su origen en la rama iraquí de al-Qaeda y constituye una derivación considerada indeseable incluso por la central desde 2004, año en que asumió el liderazgo regional Abu Musab al-Zarqawi. Su extremismo y la agresividad de sus métodos, incluso contra cualesquiera otras corrientes suníes, irritó a los propios líderes espirituales de al-Qaeda, y al-Zawahiri, su dirigente histórico en sustitución de Osama Bin Laden, fue acusado de contemplativo ante ese viraje inesperado de uno de los más destacados comandantes yihadistas. A su muerte, en 2006, al-Qaeda intentó restablecer la situación anunciando que sería reemplazado por Abu Ayyub al-Masri, más apegado a la doctrina y operativa inicial, pero la deriva iraquí parecía ya irreversible. Ese mismo año 2006, un oscuro predicador de Samarra, Ibrahim Awwad al-Badri, que con anterioridad había sido detenido y encarcelado por los norteamericanos acusados de terrorismo, aglutinó un confuso grupo de diversas facciones que dijeron constituir el Estado Islámico de Irak. Solo cuatro años después se hacía llamar Abu Bakr al-Bagdadi y lideraba una estructura que relevaba a al-Qaeda como actor principal en la zona, absorbiendo paulatinamente a sus cuadros. En abril de 2013, definitivamente independizado de al-Qaeda y tras pasar por diversas denominaciones previas, el grupo adoptaba el nombre de Estado Islámico de Irak y Levante (alDawla al-Islamiya fi-l-Iraq wa-l-Sham). La diferencia más notoria entre las dos organizaciones, insertas ambas en la corriente del salafismo ${ }^{1}$ yihadista, se

1. Movimiento reformista islámico derivado de la doctrina regeneradora de la salafiya, surgida en el siglo XIX. El único nexo compartido es el reconocimiento de la pureza de las enseñanzas del Corán, los hadices y el ejemplo del Profeta y las dos generaciones subsiguientes, que la salafiya extiende a los fundadores de las cuatro escuelas del fiqh, la jurisprudencia islámica. Entre las especificidades que presenta el salafismo podrían espigarse: la antipatía hacia el racionalismo y el modernismo reformista islámico, la beligerancia ante las demás corrientes/movimientos musulmanes, el rechazo a cualquier influencia externa, la adhesión a la escuela hanbalí, el integrismo, la ausencia de nacionalismo, etc. La mayor diferencia quizás resida en que el salafismo sí es un movimiento, en tanto aspira al desarrollo y propagación de una tendencia, y que tiene detrás un potente aparato financiador y sustentador en Arabia Saudí, que disfraza la mala imagen de su wahabismo socapa de llamarlo salafismo para la exportación.

Feminismo/s 26, diciembre 2015, pp. 101-121 
encontraba en la interpretación e implementación de la sharía, en los métodos para lograrlo y en el ámbito geográfico en que hacerlo. Mientras al-Qaeda propone una yihad descentralizada y deslocalizada, el Estado Islámico precisa de un territorio definido -básico para la reedición de un califato, aunque este sea de vocación expansiva- en el que establecer de inmediato instituciones, tribunales religiosos o policía moral sin esperar a la estabilización del conflicto. El giro definitivo, hasta la fecha, se produjo en junio de 2014 con la declaración de un nuevo califato islámico, el nombramiento de al-Bagdadi como califa y la presentación de la más general denominación Estado Islámico, que hacía expresa su intención de no circunscribirse a los espacios controlados inicialmente. En la actualidad, el llamado califato se asienta sobre la mitad del territorio sirio, con capital en la ciudad de Raqqa, y sobre un tercio fragmentado de Irak, desde las cercanías de Bagdad hasta la frontera norte con Turquía, con Mosul como capital.

La situación de la mujer, como la de la población en general, en los territorios controlados por el Estado Islámico experimentó de inmediato modificaciones basadas en la interpretación literal y rigorista del Islam que caracteriza al salafismo, siendo la imposición de un estricto código indumentario y la restricción de movimientos las primeras en implementarse. Pocas semanas después de la toma de Mosul, se hizo público un documento oficial que obligaba a las mujeres a vestir una abaya ${ }^{2}$ negra complementada por un velo igualmente negro y de doble capa cubriendo la cabeza y el rostro. Del mismo modo, se prohibía a las mujeres salir de casa sin la compañía de un mahram -un varón con el que se tiene una relación de parentesco pero con el que, al mismo tiempo y siguiendo los preceptos de la sharía, el matrimonio está prohibidolo que, de hecho, imposibilitaba a muchas el acceso a la vida cotidiana o a sus estudios. Este evidente retroceso se producía además en un país, Irak, pionero de los movimientos feministas en el mundo árabe y que había conocido figuras fundamentales en la defensa de los derechos de la mujer desde principios del siglo XX. En 1910, por ejemplo, el filósofo y poeta Jamil Sidky Zahawi (Mamouri) publicaba en el diario egipcio Al-Moayed, luego reproducido por el iraquí Tanweer al-Afkar, un artículo defendiendo la necesidad de liberar a la mujer del influjo de tradiciones sociales retrógradas. Unos años más tarde, Paulina Hassoun ponía en circulación Layla, la primera revista feminista iraquí -que publicó 20 números entre octubre de 1923 y enero de 1925, todos ellos digitalizados y disponibles en línea en el Archivo y Biblioteca Nacional

2. Túnica amplia, de cuello a pies y de manga larga, que es de uso común en la Península Arábiga y estaba menos extendido en Irak o Siria, donde el hiyab (el pañuelo cubriendo la cabeza y la vestimenta modesta) era más habitual. 
de Irak ${ }^{3}$-, y fundaba en Bagdad el Club del Renacimiento de las Mujeres (Nadi al-Nahda al-Nisaiya) junto a un nutrido grupo de activistas. En 1952, Naziha al-Dulaimi constituía la Liga Iraquí de Defensa de los Derechos de las Mujeres (Rabita al-Dafa an al-Juquq al-Maraa al-Iraqiya), luego conocida como Liga de Mujeres Iraquíes (Rabita al-Maraa al-Iraqiya), y, entre 1959 y 1962, se erigía como la primera mujer en alcanzar el cargo de ministro en todo el mundo árabe. Durante las décadas posteriores, los diferentes regímenes iraquíes protegieron o toleraron estos movimientos de mujeres y solo a principios de los 90, con la «campaña de la fe» lanzada por Saddam Hussein, empezaron a modificarse los escenarios, que no hicieron más que agravarse con el cambio de siglo y la irrupción cada vez más notoria de los partidos y doctrinas islamistas. En este sentido, el retroceso iraquí comenzó a ser especialmente llamativo a partir de 2011 cuando la ministra de Asuntos de la Mujer, Ibtihal Qasid al-Zaidi, con un largo historial de oposición a los movimientos feministas, se manifestó contraria a la igualdad de hombres y mujeres a la vez que defensora de la necesidad de la tutela y poder de los primeros sobre las segundas al proclamar que «los hombres deben ser los guardianes de la mujer y la igualdad de sexos no existe» (Ismael 189). Como culminación de este movimiento regresivo institucional, el 25 de febrero de 2014 el Consejo de Ministros aprobaba el borrador de la nueva Ley de Estatuto Personal, basada en los principios de la escuela de jurisprudencia religiosa chií, que restringía los derechos de la mujer en materias como herencias o divorcios, legalizaba la violación en el seno del matrimonio, permitía la poligamia y establecía en los nueve años la edad mínima de la mujer para contraer nupcias. Este proyecto de ley fue finalmente aparcado ante la enorme movilización nacional e internacional que suscitó y no se sometió a trámite parlamentario, pero resultaba muy ilustrativo del retroceso ideológico con respecto a la igualdad y los derechos fundamentales en el país que propugnaban sus dirigentes.

En Siria, el otro foco sobre el que se ha asentado el Estado Islámico, el recorrido de los movimientos feministas islámicos - un modelo que se distancia de manera expresa de la imitación del occidental, reivindicando sus especificidades, y para el que puede acudirse a Moghissi, Tohidi y Moghadam- se iniciaba también a principios del siglo pasado, con figuras tan reivindicativas como Mary Ajamy o Naziq al-Abid. En 1910 Ajamy fundaba la revista mensual Al-Arus, La Novia, (Talhami 20), de enorme eco social, y pedía al Congreso Nacional Sirio el voto para la mujer. Poco más tarde, Al-Abid constituía

3. <http://www.wdl.org/es/search/? institution=iraqi-national-library-and-archives\& grouping=3054>, consultado el 15-06-2015

Feminismo/s 26, diciembre 2015, pp. 101-121 
en 1919 la primera asociación femenina del país, Noor al-Fayhaa, Luz de Damasco, que publicaba una revista del mismo nombre (Talhami 11), ambas consagradas a la emancipación de las sirias. Actualmente, y pese al constante deterioro y crecientes dificultades tras cuatro años de guerra, el activismo sigue vivo de la mano de Suhair Attasi, Razan Zaitouneh o Fadwa Suleiman, que han sido por ello perseguidas por el régimen de al-Assad y han debido abandonar el país, manteniéndose conectadas y beligerantes a través de las redes sociales y las publicaciones en línea.

Es en esos países y entre esas mujeres donde el Estado Islámico ha irrumpido con la violencia y crueldad que caracteriza sus acciones, que han llevado al paroxismo la práctica de lo que el filósofo camerunés Mbembe acuñó bajo el término necropolítica y que Moisés Garduño ya le ha atribuido al constatar que en su caso «la necropolítica sería el uso de la muerte o la amenaza de muerte, gráfica y explícita, para mantener o aumentar un poder multidimensional y repartido entre actores institucionalizados y aquellos que no lo son» (129). Es indudable que la necropolítica de este grupo opera en primer lugar contra sus enemigos sobre el terreno y las poblaciones civiles sometidas a su dominio, pero también ha sido utilizada cuanto ha sido posible contra los extranjeros capturados y convertidos en moneda de cambio o presión frente a sus gobiernos. En un escalón inferior operaría también el aparato represivo y fiscalizador de las conductas colectivas e individuales, que en el caso de la mujer adquirió pronto perfiles muy determinados en manos de las brigadas femeninas al-Jansa ${ }^{4}$-más relevante y notoria, y que toma su nombre del de la poetisa preislámica del siglo VII, Tumadir bint Amr ibn al-Harz ibn al-Sharid al-Sulamiya, conocida como al-Jansa, La Chata, una figura fundamental en la poesía elegíaca de la época- y de Umm al-Rayan (Allison 25), que se constituyeron en Raqqa, Siria, poco después de que la ciudad cayera en manos del Estado Islámico a principios de 2014. Las mujeres que integran estas brigadas deben ser solteras de entre 18 y 25 años, han de dedicarse en exclusiva a la organización y obtienen un salario mensual de 25.000 liras sirias, unos 200 dólares. Reciben además alojamiento, manutención y entrenamiento básico en el manejo de armas. Debido a la calculada y lógica opacidad en que se desenvuelve el Estado Islámico, se desconoce el número exacto de componentes de estas brigadas -como de los integrantes de la organización en general-, pero los testimonios recogidos confirman la numerosa presencia de extranjeras, concretamente occidentales, cuyas salidas de Reino Unido, España, Austria o Francia rumbo al califato han sido documentadas y reflejadas en prensa.

4. Más habitualmente transcrita como Al-Khansaa, en su transcripción inglesa y francesa. 
En ese sentido, por ejemplo, el 4 diciembre de 2014, John Hall, identificaba a varias británicas en un artículo aparecido en la versión en línea del londinense Daily Mail, cuyos testimonios atribuían el liderazgo de la brigada a quien se hace llamar Umm Hamza y es conocida por el sobrenombre de la Asesina. El pasado marzo, Rafia Zakaria, en un extenso artículo de opinión en Aljazeera America titulado «ISIL's feminine mystique», -sobre el que será conveniente volver más adelante y que examinaba tanto la mística femenina del Estado Islámico como su potente eco en colectivos fuera de su territorio- estimaba en 550 las mujeres occidentales, 100 de ellas británicas, en el seno del califato.

Las funciones atribuidas a la Brigada al-Jansa podrían resumirse en las de policía moral femenina en los territorios que controlan, esto es: hacer cumplir de manera expeditiva y brutal las estrictas normas de vestimenta, actividad y ocupación del espacio público establecidas en el califato. No participan directamente en acciones militares, pero van armadas y su sola presencia y patrulla de la ciudad de Raqqa aterroriza a las mujeres, que son reprendidas, golpeadas, castigadas con flagelaciones o detenidas ante cualquier supuesta desviación de la pretendida ortodoxia impuesta. Por su parte, la brigada de Umm al-Rayan se dedica al cacheo de las mujeres en los puestos de control, tras haber tenido lugar distintos episodios de transporte de armas por parte de hombres disfrazados de mujer que las ocultaban bajo sus abayas (Allison 26).

En enero de 2015, la Brigada al-Jansa dio un significativo paso adelante con respecto a las funciones señaladas e hizo público en Internet, a través de los habituales foros yihadistas, un manifiesto sobre el papel de la mujer en el califato.

\section{El manifiesto: una breve espiga de ideas claves}

El texto se titula «Las mujeres en el Estado Islámico: manifiesto y estudio de caso» (al-Maraa fi al-Dawla al-Islamiya: risala wa taqrir) ${ }^{5}$, fue publicado el 23 de enero de 2015 coincidiendo, de manera probablemente intencionada, con el fallecimiento del rey Abdallah de Arabia Saudí, un país y unas mujeres a los que el texto alude de manera repetida, y ha circulado abundantemente en las páginas y foros yihadistas desde entonces. El hecho de que esté redactado en árabe es un claro indicio de las audiencias a las que está dirigido y contradice la práctica habitual de los comunicados y publicaciones oficiales del Estado Islámico, que son traducidos al inglés para conocimiento, consumo y escándalo occidental. Por otra parte, no fue publicado ni replicado por ninguna de

5. Original en <http://justpaste.it/almarah_resalh>, consultado el 04-03-2015.

Feminismo/s 26, diciembre 2015, pp. 101-121 
las lujosas herramientas mediáticas de las que dispone el grupo, englobadas en Al-Hayat Media ${ }^{6}$ y a las que se acude en Occidente para analizar su evolución, lo que evidencia que su público y fines no eran los habituales. En esta ocasión, el texto se dirigía específicamente a la comunidad musulmana femenina en los países árabes, con una clara intención de reclutamiento entre posibles rigoristas desencantadas con la falta de ortodoxia en sus sociedades de origen. Aun así, y al parecer para paliar el difícil acceso generalizado al estudio y análisis de sus postulados, un gabinete estratégico británico, la Quilliam Foundation, hizo pública una versión (pues no es una traducción estricta) inglesa ${ }^{7}$ en el mes de febrero. Esa en principio loable intención puede haber tenido no obstante el efecto indeseable de hacer el manifiesto inteligible para las musulmanas occidentales, que no dominan el árabe y a las que no estaba dirigido en origen, espoleando tal vez sus intenciones de unirse al califato.

En el texto en árabe se advierte expresamente al comienzo de que no se trata de un documento oficial de la organización política del Estado ni ha sido sancionado por este o sus dirigentes como marco legal para la mujer. Pese a esta advertencia, resulta inconcebible que se haya hecho público sin autorización superior y de modo autónomo por el grupo de integrantes de la brigada que dice haberlo redactado. Está compuesto de tres secciones principales que se corresponden con los motivos que, según se expone, hicieron necesaria su redacción y que se examinarán a continuación. La primera pretende esclarecer el papel de la mujer musulmana y el tipo de vida que le es propio según la tradición derivada de las enseñanzas del Profeta en la comunidad inicial de Medina. La segunda es un estudio de caso que se extiende en la supuesta realidad de la idílica existencia cotidiana de las mujeres en las zonas controladas por el califato. La tercera aborda una exposición de ejemplos de las consideradas penosas circunstancias en que viven las mujeres en Arabia Saudí, a la que se denomina «el Estado hipócrita», para ofrecerla como muestra comparativa con la anteriormente detallada en el Estado Islámico.

6. Entre sus publicaciones seriadas: Dabiq, en inglés, con 12 números publicados; Dar alIslam, en francés, tiene ya 7; Istok, en ruso, se publica desde mayo y Konstantiniyye ha aparecido el pasado junio en turco. Periódicamente además, Al-Hayat Media produce vídeos que distribuye entre los medios de comunicación internacionales. En cualquiera de sus formatos, las producciones son de una extraordinaria calidad desde el punto de vista técnico, formal y de recursos utilizados. Todas ellas son accesibles libremente, por ejemplo a través de: <http://jihadology.net/category/al-\%E1\%B8\%A5ayat-media-center/>.

7. Women of the Islamic State. A manifesto on women by the Al-Khansaa Brigade en la versión inglesa de Charlie Winter, y a la que se remiten en adelante las citas, de traducción propia, para facilitar su comparación puesto que el árabe no resulta accesible de manera tan general. 


\subsection{Las mujeres musulmanas y el fracaso del modelo occidental}

Como introducción, y antes de proceder con las especificidades femeninas, se presenta una breve proclama sobre la vida musulmana en general y cómo el capitalismo y el materialismo constituyen un escollo casi insalvable a la hora de llevar una vida piadosa en el marco de la fe islámica. A la vigorosa refutación de ambos se une la reprobación de las ciencias mundanas y el rechazo a figuras árabes fundamentales en la historia del conocimiento como Avicena, Ibn Nafis o Alhazen, cuyos estudios científicos no aportan beneficio espiritual alguno y resultan innecesarios para los musulmanes, que solo deben aspirar al conocimiento religioso. Del mismo modo, se considera que organizaciones como la UNESCO, la OMS o la FAO «difuminan los espacios entre los pueblos y eliminan los límites entre las religiones» (15). Como resultado de todo ello y por vivir en sociedades sometidas a estas influencias perniciosas, el creyente ha olvidado que la continuada alabanza de Dios es la única razón de su existencia y no reconoce la desviación de sus gobernantes ni la combate.

En el caso de la mujer, los principios que han de regir su vida se basan igualmente en la tradición de los primeros tiempos del Profeta y en «la emulación de las primeras mujeres que abrazaron la religión: Mariam, Asia, Jadiya, Fátima, Aisha, las madres de los creyentes y las esposas de los Compañeros del Profeta» (17). Que los ejemplos propuestos como modelo y canon sean los de mujeres que vivieron en el siglo VII ofrece una primera intuición de las pautas que a continuación se ofrecen y que se ponen de manifiesto en que

La tesis central de esta declaración es que la mujer fue creada para poblar la Tierra al igual que el hombre, pero, tal y como Dios quiso, fue hecha de Adán y para Adán. Además, su creador dictaminó que ser la esposa de su marido sería su tarea más elevada. Dijo Dios: Y parte de Sus signos es que os creó esposas sacadas de vosotros mismos para que encontrarais sosiego en ellas y puso entre vosotros amor y misericordia (Corán 30:21). El papel y propósito de la mujer quedan patentes en "para que encontrarais sosiego en ellas». (17)

Pero quizás porque es imposible abstraerse completamente de la impronta que indudablemente tienen incluso en esos entornos algunos arquetipos establecidos sobre la lucha de sexos y la transferencia de responsabilidad, sólo unas líneas más abajo puede leerse un fragmento ciertamente chocante, de tintes, si no feministas, sí críticos y reivindicativos.

El problema hoy en día es que las mujeres no están cumpliendo sus tareas fundamentales, el papel coherente con su más profunda naturaleza, por una importante razón: que las mujeres no tienen frente a sí un verdadero hombre debido al aumento en el número de los semihombres, que no afrontan la responsabilidad contraída con su comunidad, religión o pueblo y ni siquiera 
con sus hogares e hijos, que son mantenidos por sus esposas. [...] Esto ha obligado a las mujeres a alejarse de su verdadera función aunque sin darse cuenta. [...] Si los hombres fueran hombres, las mujeres serían mujeres. (17)

Así, la cuestión no es tanto que la mujer se haya desviado de sus originales atribuciones y funciones sino que se ha visto forzada a ello por la deriva masculina.

El llamado papel coherente con la propia naturaleza de la mujer no es otro que el divino deber de la maternidad: procrear hijos, criarlos, educarlos y prepararlos para la vida. Una tarea que, no cabe dudarlo, debe desarrollarse en el seno del hogar, haciendo uso de la específica naturaleza física y psicológica con la que Dios ha bendecido a la mujer y obteniendo así una recompensa que ninguna otra labor podría igualar. En contraposición a todo ello, el modelo occidental preferido por los infieles ha fallado desde el momento en que las mujeres se «liberaron» de esa célula familiar y abrazaron ideas corruptas. En ese sentido, es el mismo diablo que engañó a nuestros padres y los hizo salir del paraíso el que se disfraza ahora de desarrollo, progreso y cultura para continuar pervirtiendo a la Humanidad, que, en el caso de la mujer, sufre aún más los estragos de la urbanización, la modernidad y la moda. Así, la inversión de papeles basados en la estricta diferencia de género, que reside en que las mujeres sean sedentarias, reposadas y equilibradas mientras los hombres representan el movimiento y el cambio, ha dado al traste con la base de la sociedad. Del fallo del modelo occidental da prueba el propio reconocimiento de la falsedad de esas ideas, pues los gobiernos ahora otorgan salarios a aquellas que vuelven a casa a criar a sus hijos en lo que no es más que la aceptación de que son realmente amas de casa.

Finalmente, y abordando las funciones secundarias de la mujer, hay tres excepciones en las que está permitido que esta salga de casa y sirva a la sociedad en general: cuando se llama a una yihad defensiva del país y los hombres no son suficientes, para estudiar las ciencias religiosas y para ejercer como médicos o maestras, siempre en estricta observancia de las reglas de la sharía y convenientemente cubiertas. En lo relativo a otros estudios, y admitiendo que la necesidad de una cierta educación para las niñas no es contraria a ningún precepto islámico, se propone un currículo específico que se dice «una rápida y simple propuesta, no algo profundo, sólo para hacerse una idea» (24). De los 7 a los 9 años: religión y jurisprudencia islámica, lectura y escritura de árabe coránico, cálculo y ciencias naturales. De los 10 a los 12: jurisprudencia islámica aplicada a la mujer en matrimonio y divorcio, profundización en el árabe coránico, cocina y costura básicas. De los 13 a los 15: inmersión en la sharía, destrezas relacionadas con la crianza de los hijos, historia islámica. 
La educación debe interrumpirse a esa edad puesto que, aunque se considera legítimo que una niña pueda casarse a la edad de 9 años, «la mayoría de las muchachas puras estarán casadas a los 16 o 17, mientras que aún son jóvenes y activas. Los jóvenes varones de estas generaciones gloriosas lo estarán a los $20 »$ (24). En cuanto a las mujeres que se ven obligadas a servir a la comunidad fuera de casa, el manifiesto se extiende en una serie de propuestas que ni los más aguerridos sindicalistas, defensores de la conciliación y discriminación positiva o feministas se verían con ánimo de presentar en Occidente. A modo de ejemplo, la mujer: no trabajará más de tres días a la semana ni en jornadas que la obliguen a abandonar su casa durante largas horas, ha de tener permisos retribuidos por enfermedad de sus hijos o ausencia de su marido, se le otorgarán dos años de permiso por maternidad y ha de disponer de un lugar en los centros de trabajo donde sus hijos estén atendidos hasta alcanzar la edad escolar y ella pueda pasar a verlos de tanto en tanto. Estos planteamientos, aún por concretarse en la realidad cotidiana, no hacen más que insistir propagandísticamente en el modo de vida ideal que las mujeres disfrutan en el califato y que se desarrolla en el punto siguiente.

\subsection{La Arcadia Feliz islámica en el nuevo califato}

Para comprobar la realidad de la vida cotidiana o las instalaciones y servicios médicos, educativos y recreativos a disposición de las mujeres en el Estado Islámico no es preciso más que darse un paseo por las calles de Raqqa o Mosul, donde, según el manifiesto, la felicidad es más que palpable y ha supuesto una liberación tras haber sufrido la opresión colonial primero y la de influencia chií de los gobiernos nacionales después. Esto resulta especialmente meritorio teniendo en cuenta que el enemigo está a las puertas y bombardea continuamente ambas ciudades, que, pese a ello, siguen con su paciente labor de construcción y establecimiento de instituciones, administración y servicios.

Se destaca en primer lugar el feliz retorno al velo islámico, durante años prohibido o desincentivado, que guarda la modestia de la mujer y la protege de exposiciones indeseables y de las continuas humillaciones sufridas en el pasado. Las mujeres sunníes fueron durante años raptadas, torturadas y violadas sin freno alguno, en el marco de una inseguridad generalizada; ahora, gracias al restablecimiento de los castigos dimanados de la sharía, la seguridad reina en el califato. Además, el garantizado acceso de la mujer a los tribunales religiosos de justicia -donde el nivel de corrupción es cero- hace que por primera vez esta pueda ser oída en la libre exposición de sus asuntos. Incluso «Si una cristiana acude a los tribunales y declara su conversión al Islam, disfruta 
igualmente de una protección absoluta frente al daño y el abuso, sin importar que sea paternal o de cualquier otro tipo» (30).

El estado de pobreza material en que se había vivido tradicionalmente en provincias sunníes de Irak como Nínive, cuyos recursos eran explotados por el gobierno chií sin revertir en modo alguno en la población, y que sufrían especialmente las mujeres, es cosa del pasado. Ya no les es preciso recurrir a la limosna puerta a puerta porque el califato la ha institucionalizado a través de la Cámara del Zakat -la limosna religiosa que constituye uno de los cinco pilares del Islam- y ninguna mujer se ve ahora en la necesidad de rebajarse a pedirla pues se le proporciona de oficio en caso de necesidad al igual que la atención sanitaria. La medicina y los hospitales han reverdecido tras años de desidia gubernamental y ahora disponen de técnicas punteras al servicio de la población en general y de la mujer en particular, que es beneficiaria de atención especializada para ella y sus hijos; una circunstancia al parecer revolucionaria y desconocida hasta ahora. Como lo es también el hecho de que «El Estado trata de impedir la mezcla de hombres y mujeres y trabaja tanto como le es posible para lograrlo; así, es el primer y único sitio del mundo donde se proporciona atención sanitaria completa y en modernos hospitales sin mescolanza» (33). Esa mezcla indeseable ha sido barrida también de las aulas aunque, se hace especial hincapié, no se ha prohibido el acceso de la mujer a ninguno de los niveles educativos, universidad incluida. Antes al contrario, se han puesto en marcha institutos específicos para la enseñanza femenina de la sharía y la jurisprudencia islámica, además de adecuar la universidad de Mosul para la completa separación de sexos sin ahorrar esfuerzos ni recursos.

En Raqqa, el feudo sirio, la mejora de la situación ha sido incluso más evidente, convirtiéndola en meta y destino anhelado por muchas familias emigrantes, árabes y no árabes, que huyen de la tiranía y la opresión en sus países o del elevado número de facciones en lucha en Siria, sobre cuyos numerosos errores y aspectos negativos no se quiere incidir porque son de general conocimiento. Esa afluencia de extranjeros a la ciudad no es tan patente en Mosul y constituye la única diferencia entre las dos comunidades, pues el Estado no establece ninguna otra en cuanto al acceso y la distribución equitativa de los recursos entre migrantes y naturales.

El idílico y propagandístico retrato de esta Arcadia Feliz musulmana parece la culminación de las aspiraciones de Al-Medina al-Fadila (la ciudad virtuosa) del pensador y jurista del siglo X Ibn al-Farabi, aunque sin sustento filosófico o intelectual alguno, y tiene como principales destinatarias a las mujeres del Golfo Pérsico, Arabia Saudí en concreto. A la exposición de su lastimosa vida se dedica la última sección del manifiesto. 


\subsection{La situación de la mujer en Arabia Saudí}

El tomar a Arabia Saudí como modelo indeseable no es casual, pues se inscribe en la pugna que con ese país mantiene el Estado Islámico por erigirse como la representación más cabal y ortodoxa del salafismo actual, y se debe a que «nos produce dolor de cabeza el oír a sus partidarios y a los encandilados por ese modelo decir que protege a la mujer musulmana y le proporciona todos sus derechos sin escatimar» (38). Eso es evidentemente falso, dicen, y las diferencias entre el califato y el Estado hipócrita son claras y obvias a favor del primero, sobre todo si se tiene en cuenta la enorme distancia que separa sus fechas de constitución y los recursos de que disponen uno y otro. Las mujeres saudíes se ven sometidas al miedo, la arbitrariedad, la occidentalización, la pobreza y la injusticia, ilustradas incluso con ejemplos de testimonios que se pretenden directos. Los métodos que el Ministerio del Interior, por ejemplo, emplea contra las mujeres que dan testimonio de su fe no difieren de los utilizados por los llamados perros de la CIA y no es extraño que sean sacadas de sus casas, encarceladas sin juicio y arrojadas en prisiones donde son violadas. En el excepcional caso de que sean presentadas ante un juez la situación es aún más terrible, porque no cabe esperar nada bueno de tribunales que «basan sus resoluciones en el Talmud o el Evangelio de Juan. En ausencia del Corán, no queráis saber las calamidades que acontecen a las mujeres inocentes y castas» (38). En cuanto a la occidentalización, la barbarie y el salvajismo a los que su influencia somete a la mujer en el Golfo Pérsico en general es evidente con solo salir a la calle porque

Hoy en día, las mujeres pueden trabajar junto a hombres en establecimientos como los bancos, donde no están separadas de ellos ni por una fina hoja de papel. Se les permite mostrarse en las fotos de los documentos de identidad y aquella que no lo hace afronta grandes dificultades. Se ha abierto de par en par la puerta a becas en Occidente e incluso funciona en Jeddah una universidad corrupta -quiera Dios que se la trague la tierra junto con toda su gente-, en la que varones y hembras pueden mezclarse en los pasillos como si estuvieran en un infiel país europeo. (39)

Esa universidad corrupta a la que se alude debe de ser la King Abdullah University of Science and Technology (KAUST), la primera y única mixta hasta ahora en el reino, epítome de la occidentalización indeseable que permite la interacción entre sexos y muestra inequívoca del tipo de ofensas que este gobierno apóstata inflige a sus mujeres. Un gobierno que, se nos dice, enarbola una única medida de pretendida protección de las mujeres al prohibirles conducir y que resulta del todo incongruente porque no es conforme a ningún precepto religioso y, además, se produce en un país que tolera la proliferación 
de crímenes en sus calles. Un Estado que da apoyo material y financiero a cadenas de televisión como al-Arabiya, compendio de prostitución y corrupción, donde se proyecta una mala imagen de las mujeres veladas y se permite a las inmorales expresar libremente sus opiniones. Un lugar en el que a la mujer no solo se le permite trabajar sino que a menudo se la fuerza a ello, desplazándola lejos de su familia y poniéndola en peligro obligándola a usar medios de transporte que aprovechan esos trayectos para traficar con drogas.

Como epílogo a todo lo anterior, y en el mismo lenguaje simplón que preside todo el documento y que se examinará en el apartado siguiente, se interpela a las posibles lectoras: «Resumiendo, esta es la penosa situación de las mujeres en el Golfo. También hemos dado una idea de la vida de las mujeres en el estado califal. ¿Qué imagen es mejor? ¿Cuál es más pura? ¿En qué hogar merece más la pena vivir?» (40).

\section{El manifiesto: estilo y peculiaridades}

Hasta ahora, los escritos y manifiestos del Estado Islámico -como puede comprobarse en las publicaciones mencionadas con anterioridad- han sido muy cuidados desde el punto de vista formal y de utilización del lenguaje. Que sus manifestaciones reflejen visiones ciertamente perturbadoras no ha sido incompatible con un estilo cultivado y calculado, así como con un profundo conocimiento del Corán y la Sunna para sustentar sus enunciados. En el número 9 de Dabiq, por ejemplo, una tal Umm Sumayyah al-Muhajirah -es decir, una inmigrante, no una local de origen-firma un artículo, de la página 44 a la 48 , titulado « ¿Esclavas o prostitutas? $»^{8}$, en el que tanto la argumentación histórica y coránica como su fundamento en la tradición de los hadices y sus transmisores más reputados para sostener lo indefendible es irreprochable desde el punto de vista de la exégesis. Supuestamente escrito por una mujer, su presentación, estructura y discurso se inserta perfectamente en los acostumbrados cánones que enmarcan todas las exposiciones teóricas de la organización.

Esta tendencia se quiebra de manera evidente en el manifiesto de la Brigada al-Jansa, que carece de cualquiera de las características distintivas de las producciones escritas del califato. Su estilo es simple, poco pulido e incluso coloquial, y el lenguaje se asemeja al de los manuales infantiles en más de una ocasión. Las referencias coránicas se limitan a la reproducción de algunos versículos sin ahondar en su interpretación y el habitual recurso a la doctrina

8. <https://azelin.files.wordpress.com/2015/05/the-islamic-state-e2809cdc481biq-magazine-9e280b3.pdf>, consultado el 29-06-2015. 
de los eruditos tradicionales islámicos está prácticamente ausente en el texto. Los ejemplos se reducen a anécdotas elevadas a la categoría de pautas y el planteamiento general remite a una elaboración deficiente e intelectualmente pobre, que quizás aspira a una accesibilidad sin barreras pero resulta en enunciados como

Es el diablo el que las desviste, sacándolas de su paraíso de cobertura y decencia, y las anima a gastar enormes cantidades de dinero para cambiar la creación Divina, pidiendo a los cirujanos que les cambien la nariz, las orejas, la barbilla y las uñas. Esa es la «verdadera moda femenina»: cosas colgando de las orejas, vello afeitado en unas partes y en otras no, y otras cosas que no gustan al ojo del espectador. (21)

que recuerdan, bien que involuntariamente seguro, a los de las revistas de belleza y consejos dirigidas a sectores muy específicos. Este tono ligero, de mensajes contundentes, de ejemplos fácilmente digeribles e impacto directo permiten intuir el retrato de las posibles destinatarias en la región. Sin duda son fundamentalmente, tal y como reconoce el texto, mujeres de la zona del Golfo Pérsico, pero desde luego no las pertenecientes a las élites cosmopolitas que pueblan los centros comerciales allí o en Londres. El objetivo lo constituye más bien el colectivo rigorista que siente como una humillación y una desviación inconcebible cualquier atisbo de modernización o flexibilización en la vida de pureza islámica que creen les corresponde y las dignifica. Ese colectivo no solo existe, por singular que ello parezca en Occidente, en todo el mundo árabe y musulmán, -con movimientos femeninos revivalistas, como Qubaysiya en la propia Siria, que han sido tratados por Asma Sayyed (2013)sino que conoce un crecimiento notable en los últimos años y está compuesto fundamentalmente por mujeres jóvenes. Unas mujeres que entienden como deseable para ellas y agradable a los ojos de Dios que

Desde el establecimiento del califato, la costumbre de cubrirse y el uso del hiyab regresaron al país y la decencia se instaló en él. Ahora, las mujeres pueden viajar a Raqqa para ver a sus familias sin tener que enseñar sus caras a un solo inspector. Ha vuelto el respeto por sus cuerpos y se los protege de los ojos de los mirones de corazones corruptos. Se evitan ahora las causas de sus humillaciones: se confiscaron las ropas reveladoras y se prohibieron las fotos escandalosas en muros y expositores. Los musulmanes fueron purificados con permiso de Dios. (28)

Por otro lado, tanto la ausencia de la acostumbrada y alambicada retórica religiosa, que suele ser muestra de un conocimiento profundo aunque sesgado del Islam y sus textos fundamentales, como la curiosa presencia de pinceladas extrañamente occidentales en el abordaje de algunas cuestiones, sustentarían también la impresión de que el texto es obra si no de extranjeras sí al menos 
de gente con una instrucción religiosa básica. La inclusión de las ya citadas referencias a la lucha de sexos -la mujer ha dejado de ser mujer porque los hombres han abdicado de sus responsabilidades como tales-, o la reivindicación de exigentes condiciones laborales específicas para las mujeres, remiten a una formación o influencia occidental por más que se vea sepultada por propuestas que contradicen esos valores.

\section{Conclusiones}

Mary Nash, en su obra Mujeres en el mundo. Historia, retos y movimientos, destaca que la histórica diferencia de sexos, sostenida en una argumentación que apela tanto a la naturaleza como a la religión, ha sido sustituida modernamente por la de género, que solamente ha secularizado la desigual división sin erradicar la ideología tradicional. Las funciones de la mujer siguen estando marcadas y delimitadas por una mentalidad patriarcal de subordinación, que estipula en cada momento y sociedad aquello a lo que esta debe razonablemente aspirar y aquello que le está si no vedado sí fuertemente restringido. En las sociedades árabes, donde la cultura occidental está generalmente encuadrada en la otredad, el feminismo islámico debe afrontar además una doble lucha al oponerse a los patrones subordinadores: de un lado, el propio dogmatismo de las doctrinas salafistas en alza y, de otro, la casi inevitable atribución de contaminación occidental y su todavía vigente conexión con el legado colonial.

Paralelamente, el poder de atracción que un movimiento regresivo de estas características tiene entre los musulmanes, hombres y mujeres, de Occidente, que abandonan las sociedades en que han nacido y se han criado dejándolo todo atrás o, incluso y en el caso de las mujeres, llevando a sus hijos consigo, es una paradoja de difícil asunción por parte de las sociedades emisoras. Pero los motivos empiezan a ser identificados y debatidos en ellas, sacando a la luz disfunciones sociales y exacerbando la pugna entre las distintas aproximaciones incluso en el terreno político, que no duda en trufar el debate de tintes xenófobos al calor de cada nuevo episodio de salida detectado. En palabras de Žarkov:

Los políticos esencialistas y de derechas tienen una respuesta simple: son inmigrantes musulmanes que jamás adoptaron los valores democráticos occidentales simplemente porque el Islam es ajeno a ellos, una religión premoderna cuyas escrituras inspiran y apoyan prácticas bárbaras y asesinas. [...] Las posturas liberales y no esencialistas apelan al impulso de una serie de factores: el sentimiento de exclusión de las sociedades occidentales en las que crecieron y una romántica e idealista búsqueda de esa inclusión en una comunidad más acogedora entre ellos. (3) 
Los motivos de las mujeres occidentales para emigrar al califato están siendo muy recientemente examinados y es fundamental remitirse al análisis de Edwin Bakker y Seran de Leede, del International Centre for Counter-Terrorism con sede en La Haya, que estiman el número de ellas en unas 550 sobre el total de 4.000 combatientes extranjeros en Siria. Entre los motivos registrados cabría destacar, además del deber ideológico y religioso de apoyar la yihad: «la atrayente idea de un nuevo comienzo, aderezada por los sentimientos de no pertenencia y fracaso [...]. Además de la atracción por la aventura y el viaje a tierras extrañas, que pueden también tener su importancia para ambos sexos» (5). Pero no conviene quedarse en el simple retrato de un romanticismo desesperanzado pues, en el caso concreto de las mujeres, aparece con abundancia la manifestación de que «desean vivir bajo las leyes de Dios en un Estado puro e islámico, donde serán tratadas con honor en una tierra nueva y santa que están ayudando a construir» (6). Y en este sentido quizás corresponda acudir de nuevo a Rafia Zakaria y lo que en su artículo denomina «la mística femenina del Estado Islámico». Una mística elaborada y que responde a una estructuración ideológica sólida, aunque bárbara y retrógrada, que resulta deseable en algunos círculos y que nos lleva a interrogarnos sobre los que creemos misteriosos motivos por los que las musulmanas occidentales están abrazando los postulados más radicales y contrarios al feminismo.

El discurso fundamentalista e integrista cristiano occidental, por su parte, no difiere sustancialmente del que se ha analizado en el manifiesto y el antifeminismo, en voz y militancia de hombres y mujeres, aparece en muy diversas corrientes que nada tienen que ver con el Islam. En Estados Unidos, Promise Keepers ${ }^{9}$, un movimiento integrista masculino fundado en 1990 por Bill McCartney y extendido luego a Canadá y Nueva Zelanda, constituyó el modelo en que se inspiró la organización cristiana femenina Women of Faith, que apela también a «la necesidad de una renovación espiritual de la mujer, a la vez que subraya que su sumisión a Dios y al cabeza de familia masculino son un mandato bíblico y la clave para la felicidad y la realización personal» (Erzen 238). En toda Europa, como en Norteamérica, los movimientos antiabortistas apelan continuamente al retorno de las mujeres a su verdadera naturaleza, la de la maternidad, y entienden cualquier legislación en ese sentido como un ataque a la familia y a la integridad de la mujer en su más noble función.

Que el manifiesto es árabe y musulmán es una realidad indiscutible y de particularidades específicas, sumamente condicionadas por el ideario salafista

9. <https://promisekeepers.org/>, consultado el 20-06-2015. 
yihadista en el que se originan; que varias de sus convicciones o propuestas resulten exóticas e inauditas fuera de ese entorno no lo es tanto. Están inscritas en una ola de fundamentalismo postfeminista detectado en otras sociedades y ámbitos geográficos y políticos distantes y se examinan con estupor en los últimos años. El 28 de junio de 2014, en el marco de la I Conferencia Internacional sobre Problemas de los Hombres celebrada en Detroit, los tres primeros ponentes fueron mujeres: Anne Cools, una senadora canadiense; Erin Pizzey, novelista británica, exfeminista y fundadora de una red de albergues para mujeres; y Tara Palmatier, psicóloga norteamericana. La primera, con una trayectoria política de más de treinta años -es senadora desde 1984 y fue la primera senadora negra de Canadá y toda América del Norte-, introdujo incluso la palabra «ginocentrismo» en 1999 al referirse a la perversa influencia feminista en el Tribunal Supremo de su país y en la página Web de la organización «A voice for men ${ }^{10}$ defiende que

La teoría feminista de género es un ejemplo de fraude intelectual y está basada en la «filoginia», el tribalismo y la «misandria». Una teoría que acosa a la vida social y política de este país. Es depredadora y busca dominar y aterrorizar. Es un desorden de la personalidad en el cuerpo político de esta nación.

La segunda -cuyo pensamiento se refleja y resume en su página $\mathrm{Web}^{11}$ - califica al feminismo de conspiración perversa y acusa al movimiento que un día apoyó de ser un complot marxista radical para volver a las mujeres en contra de los hombres. La tercera, también muy activa en su página en Internet ${ }^{12}$, detecta que los niños crecen avergonzados porque se mitifica a las madres mientras se humilla a los padres y que a causa del feminismo las mujeres sufren trastornos narcisistas de la personalidad cada día en mayor medida. Aún dice más; en su opinión, en el mundo que el feminismo ha redefinido, los hombres están avergonzados y las mujeres son desvergonzadas.

No podía faltar a ese congreso Karen Straughan, antifeminista con vídeos en Youtube que acumulan millones de visitas y un sitio Web con un programa de radio que se dice para las mujeres que no culpan a los hombres. Curiosamente, ese sitio Web se llama Honey Badger Brigade ${ }^{13}$-un juego de palabras entre el literal de la Brigada del Tejón de la Miel y el argot de Brigada Me Importa una Mierda- y, más curiosamente aún, en su página puede leerse también un manifiesto, el Badgerfesto. Y no es necesario acudir a países

10. <http://www.avoiceformen.com/feminism/feminist-governance-feminism/canadiansenator-anne-cools-ongoing-battle-against-gender-feminism/>, consultado el 23-06-2015.

11. <http://www.erinpizzey.com/index.html>, consultado el 29-06-2015.

12. <https://shrink4men.wordpress.com/about/>, consultado el 28-06-2015.

13. <http://honeybadgerbrigade.com/>, consultado el 30-06-2015. 
extranjeros para disponer de ejemplos de este revivalismo tradicionalista y antifeminista. En nuestro país, el arzobispado de Granada editó en 2013 un manual escrito por la periodista italiana Constanza Miriano bajo el explícito título Cásate y sé sumisa, que se colocó inmediatamente en el primer puesto de los libros más vendidos por Amazon España y cuya retirada pidió incluso la entonces ministra de Sanidad, Ana Mato.

Para finalizar, la historia reciente pone de manifiesto que tanto Irak como Siria han sido países en los que las mujeres han visto sus derechos protegidos por una legislación alejada del rigorismo y la interferencia religiosa; con acceso a la educación, a la autonomía personal y a la participación en la vida pública; con una visible pluralidad de actitudes, atuendos y grados de adhesión a modos de vida tradicionales u occidentalizados, que no se veían abiertamente coartados por el poder político o religioso. El impacto que en estas sociedades y mujeres ha tenido la llegada del Estado Islámico y su potente aparato represor es fácilmente imaginable, pero coexiste, guste o no, con el efecto de llamada que ejerce en mujeres del exterior. Este poder de convocatoria viene además multiplicado por una intensa presencia en los medios de comunicación y las redes sociales, auténtica zona de combate virtual de la llamada Yihad 2.0 y donde estas organizaciones están ganando indiscutiblemente la batalla narrativa mientras afrontan poca o ninguna contranarrativa.

\section{Referencias bibliográficas}

Al-Farabi, Abu Nasr. La ciudad ideal. Ed. Miguel Cruz Hernández. Trad. Manuel Alonso Alonso. Madrid: Tecnos, 2011.

Allison, Jessica y Logan Barnes. «The Islamic State of Iraq and the Levant's Strategic Treatmen and Use of Women». The George Washington University, The Institute for Middle East Studies, Imes Capstone Paper Series, May (2015). <https://www.gwu.edu/ imes/assets/docs/Capstone\%20Papers-2015/ Allison\%20and\%20Barnes\%20Capstone\%20Final\%20050515.pdf>

BAKKER, Edwin y Seran de Leede. «European Female Jihadist in Syria: Exploring an Under-Researched Topic». ICCT, Background Note, April (2015).

$<$ http://www.icct.nl/download/file/ICCT-Bakker-de-Leede-European-FemaleJihadists-In-Syria-Exploring-An-Under-Researched-Topic-April2015.pdf>. 29 de junio de 2015.

EL-HusSEINI, Rola. «Gender and the Jihadist: Radical Islam and Women». Atlantic Council, March (2015). <http://www.atlanticcouncil.org/blogs/menasource/ gender-and-the-jihadist-radical-islam-and-women>. 24 de junio de 2015. 
ERzEN, Tanya. «Liberated Through Submission? The Gender Politics of Evangelical Women's Groups Modeled on the Promise Keepers». The Promise Keepers. Essays on Masculinity and Christianity. Ed. Dane S. Claussen. Jefferson, North Carolina: McFarland \& Company, Inc., 2000, 238-254.

GARDUÑO GARCÍA, Moisés. «La necropolítica de la Organización del Estado Islámico». Revista de Relaciones Internacionales de la UNAM 17 (2013): 127-152. Hoyle, Carolyn, Alexandra Bradford y Ross Frenett. «Becoming Mulan? Female Western Migrants to ISIS ». Institute for Strategic Dialogue. Research and Policy Papers 1 (2015).

ISMAEL, Tareq Y. y Jacqueline S. Ismael. Iraq in the Twenty-First Century : Regime Change and the Making of a Failed State. Oxon : Routledge, 2015.

HALL, John. «Revealed : How 'up to 60' women rule ISIS's capital by fear. Merciles 'Jihadettes' order executions, punishment lashings, and manage sex slave brothels». Daily Mail, 4 diciembre 2014. <http://www.dailymail.co.uk/news/ article-2858819/Up-60-British-Jihadette-women-rule-ISIS-s-capital-fear. html>. 24 de junio de 2015.

MAMOURI, Ali. «Women's movement in Iraq faces setbacks ». Al Monitor, 18 marzo 2014.<http://www.al-monitor.com/pulse/originals/2014/03/iraq-women-rightschallenges-setbacks.html\#>. 20 de junio de 2015.

Mbembe, Achille. Necropolítica. Barcelona: Melusina, 2011.

Miriano, Constanza. Cásate y sé sumisa. Experiencia radical para mujeres sin miedo. Granada : Nuevo Inicio, 2013.

MoghadAm, Valentine M. «Islamic Feminism and Its Discontents :Toward a Resolution of the Debate». Signs, 27-4 (2002): 1.135-1.171

MoGHISSI, Haideh. Feminism and Fundamentalism. The limits of postmodern analysis. London: Zed Books Ltd, 1999.

NASH, Mary. Mujeres en el mundo. Historia, retos y movimientos. Madrid: Alianza, 2004.

SAYYED, Asma. Transmission of Religious Knowledge in Islam. Cambridge: Cambridge University Press, 2013.

TalHami, Ghada. Historical Dictionary of Women in the Middle East and North Africa. Lanham: Scarecrow Press Inc., 2013.

TOHIDI, Nayereh. «Feminismo islámico. Negociando el patriarcado y la modernidad en Irán». Descolonizando el feminismo: teorías y prácticas desde los márgenes. Eds. Liliana Suárez Navaz y Rosalva Aída Hernández Castillo. Madrid: Cátedra, 2008.

Women of the Islamic State. A manifesto on women by the Al-Khanssaa Brigade. Trad. Charlie Winter. London: Quilliam Foundation (2015). < http://www. quilliamfoundation.org/press/quilliam-translation-and-analysis-of-islamicstate-manifesto-on-jihadist-brides/>. 25 de junio de 2015. 
El manifiesto de la Brigada al-Jansa sobre el papel de la mujer en el nuevo califato... 121

ZAKARIA, Rafia. «ISIL's femenine mystique». Aljazeera America, 24 marzo 2015. $<$ http://america.aljazeera.com/opinions/2015/3/isils-feminine-mystique. html>. 24 de junio de 2015.

ŽARKOV, Dubravka. «Reflecting on faith and feminism». European Journal of Women's studies 22.1 (2015): 3-6. 